\title{
Population Frequencies and Altered Remodeling Mechanisms in Normal Medullary Stenosis
}

\author{
STANLEY M. GARN, GAIL H. DAVILA AND CHRISTABEL G. ROHMANN \\ Center for Human Growth, University of Michigan, Ann Arbor, and \\ The Fels Research Institute, Yellow Springs, Ohio
}

\begin{abstract}
As shown in 2065 women aged 18 to 45 years from seven countries of Central and North America, the population frequency of normal medullary stenosis ranges from under $2 \%$ to nearly $7 \%$. In this condition, endosteal apposition may begin in infancy and continue through the fourth decade with a compensatory reduction in the rate of subperiosteal apposition, leading to an approximately normal cortical cross-sectional area contained in a smaller subperiosteal envelope.
\end{abstract}

Medullary stenosis, characterized by reduced medullary cavity widths, growth retardation, disorders of calcium metabolism and probably inherited as a simple mendelian dominant has recently been established as a clinical entity (Kenny and Linarelli, '66; Caffey, '67). Reduced medullary cavity widths also exist in apparentlynormal individuals, the frequency of such medullary reduction varies from population to population, and the course of transverse bone growth is then considerably altered from the normal course (Garn, Rohmann and Harshman, '68).

Defining medullary stenosis as medullary cavity width in the second metacarpal at midshaft in the adult female less than $1 \mathrm{~mm}$ (see fig. 2) and as studied in 2065 women from seven countries of Central and North America, there is considerable variation in the frequency of this trait. Among women aged 18 to 45 , the frequency of normal medullary stenosis ranges from under $2 \%$ in Nicaragua to nearly $7 \%$ in Costa Rica (table 1). In four of these countries (Nicaragua, Panama, El Salavador and Guatemala) the frequency of medullary stenosis is significantly smaller than in Costa Rica by $x^{2}$ test. Costa Rica, then, emerges as the country with the highest frequency of medullary stenosis in the present sense. In a general way, the frequency of medullary stenosis as shown in the metacarpals appears to be a function of the frequency of European genes.

Moreover, the high frequency of medullary stenosis in Costa Rica is associated with increased size variance of the medullary cavity diameter rather than overall size reduction in this width. ${ }^{1}$ As shown in table 1, Costa Rica has the highest medullary size variance (as measured by $\sigma^{2}$ ), the $F$ test is then positive for all six comparisons and it is significant at $p=0.05$ or better in comparison with Guatemala, El Salvador, Nicaragua, and Panama. Furthermore, analysis of the distributions countryby-country indicates a tendency towards skewness at the bottom end of the medullary size distribution, and, especially in Costa Rica, a secondary mode well below $0.9 \mathrm{~mm}$.

Now adult medullary stenosis could be due to a failure of endosteal resorption during childhood, or to an excess of endosteal apposition during adolescence and young adulthood (cf. Garn, Rohmann, Wagner and Davila, '68). To resolve this problem, we have turned to our serial, longitudinal data from Southwestern Ohio, selecting subjects of each sex with the lowest possible fully adult values of medullary width. These included two males, numbers 268 and 112 , with medullary widths of 0.60 and $0.45 \mathrm{~mm}$ (T17 and T16) at ages 24 and 33 years respectively. It also includes two females (151 and 097) with minimum medullary cavity widths of 0.80 and $0.40 \mathrm{~mm}$ ( $\mathrm{T}$-scores 23 and 22 at ages 18 and 34 years, in turn ). These four indi-

1 Although Costa Rican women include the largest percent with medullary widths under $1.0 \mathrm{~mm}$, the mean medullary cavity width is not significantly different from that for the other populations considered except for El Salvador, where it is actually slightly largex $(t=2.62)$. 
TABLE 1

Medullary stenosis in 2065 adult women aged 18-45

\begin{tabular}{|c|c|c|c|c|c|c|}
\hline \multirow[t]{2}{*}{ Country } & \multirow[t]{2}{*}{$\begin{array}{l}\text { No. } \\
\text { examined }\end{array}$} & \multicolumn{2}{|c|}{ Under $1.0 \mathrm{~mm}$} & \multirow{2}{*}{$\begin{array}{l}\chi^{2} \text { vs. } \\
\text { Costa } \\
\text { Rica }\end{array}$} & \multirow{2}{*}{$\begin{array}{c}\sigma^{2} \\
m m m\end{array}$} & \multirow{2}{*}{$\begin{array}{l}\text { Fvs. } \\
\text { Costa } \\
\text { Rica }\end{array}$} \\
\hline & & no. & $\%$ & & & \\
\hline Nicaragua & 309 & 6 & 1.9 & $10.48^{1}$ & 0.69 & $1.25^{2}$ \\
\hline Panama & 340 & 8 & 2.3 & 9.531 & 0.61 & $1,41^{2}$ \\
\hline El Salvador & 248 & 7 & 2.8 & $5.41^{1}$ & 0.53 & $1.62^{2}$ \\
\hline Guatemala & 389 & 13 & 3.3 & $6.97^{1}$ & 0.61 & $1.41^{2}$ \\
\hline Honduras & 324 & 13 & 4.0 & 3.26 & 0.77 & 1.12 \\
\hline Ohio (U.S.A.) & 119 & 5 & 4.2 & 1.20 & 0.81 & 1.06 \\
\hline Costa Rica & 336 & 22 & 6.5 & - & 0.86 & - \\
\hline
\end{tabular}

1 Significantly different from Costa Rica by $\chi^{2}$ test and table X in Walker and Lev ('67).

2 Medullary size variance $\left(\sigma^{2}\right)$ significantly greater in Costa Rica by $F$ test.

viduals are clearly well within the category of adult medullary stenosis as defined above. For the two males, medullary cavity widths were below expectancy even at birth and decreased systematically thereafter by endosteal apposition, as shown in figure 2. In comparison to the Ohio population norm, these two males not only decreased in medullary width during childhood (the normal period of medullary increase) but the tendency to endosteal apposition rather than endosteal resorption continued beyond early adulthood. For the two females, Subjects 151 and 097, the major deviation from expectancy was in the greatly exaggerated rate of endosteal apposition during adolescence, continuing well into adulthood. All four subjects exaggerated the steroid-mediated phase of endosteal apposition and these selected individuals further show that the tendency towards medullary stenosis can be both evidenced early and continued late.

Now if the behavior of the endosteal surface in normal medullary stenosis is in many respects the reverse of normal, what about apposition at the subperiosteal surface and what about net cortical area at midshaft? Here we can neatly compare the 22 index women from Costa Rica, previously summarized in table 1 , to the total of 234 women in the selected age range from that country. Expectably, medullary cavity width is highly reduced in this group, to $24 \%$ of the age-specific norm. Further, the subperiosteal diameter is slightly reduced, i.e. $91 \%$ of normal. Moreover, cortical thickness is itself increased to a total of $124 \%$ of normal. Finally, with a smaller medullary cavity width, smaller subperiosteal diameter, but increased cortical thickness, cortical area at midshaft is least reduced, being $93 \%$ of normal for the total group of Costa Rican women aged 18 to 45 years.

In other words, when endosteal resorption is replaced by endosteal apposition in the course of bone growth, there is a slight compensatory reduction in the rate of subperiosteal apposition, but little if any difference in net cortical area and hence in the total amount of bone laid down over time. While the directions and rates of subperiosteal and endosteal apposition and resorption are clearly different in this condition, the ratio of apposition to resorption, and hence the area of cortical bone, are rather little altered.

\section{ACKNOWLEDGMENTS}

This research was supported by grants AM 13378 and FR-00222 (Computer) and Contract PII-43-65-1006 of the Advance Research Projects Agency (Project AGILE) and was monitored by the Nutrition Program, National Center for Chronic Disease Control, Public Health Service, Department of Health, Education and Welfare, under ARPA Order number 580, Program Plan number 298.

The authors wish to thank John P. Dorst for providing radiographic examples of the clinical form of medullary stenosis with growth retardation, Marianne Schulman for figure 2, and Dorothy J. Gross for completing the manuscript. Initial observations on medullary stenosis in Costa Rica were made by Jeremy Brigham. 

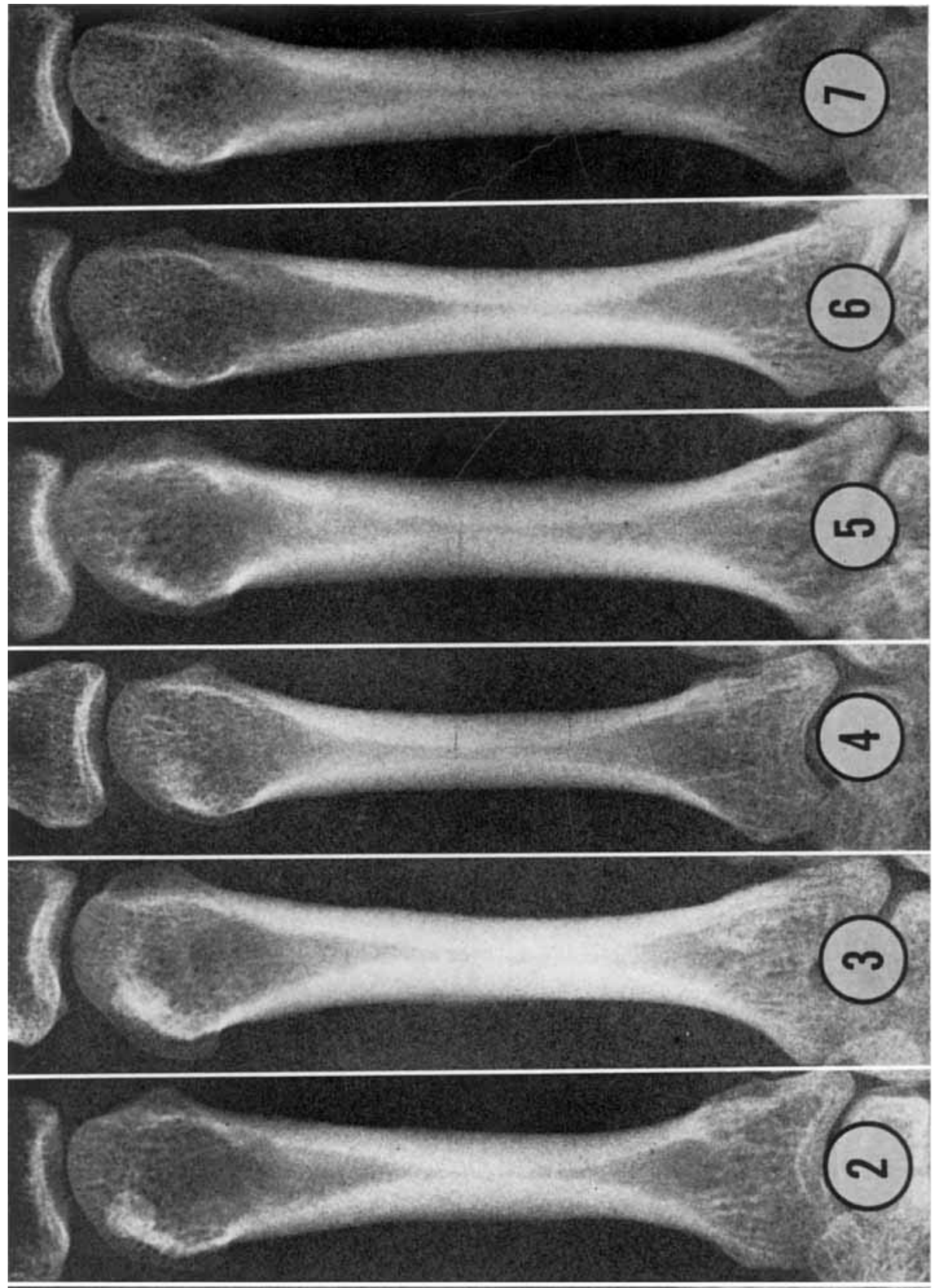

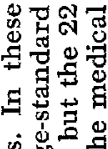

क.

帘

政 कo

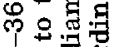

의 영

व.

喿可司

政

동 융

명 명

政

घ द्व

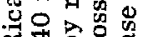

平主品

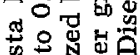

o. N

ठ웅

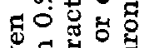

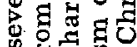

tै

굴

Q

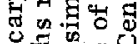

ज 5

ष्ठ

on

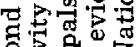

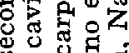

(

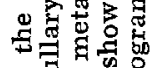

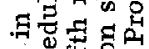

की 물 क्ष

苟的西

है

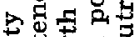

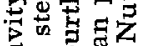

은

용

골

콩 뭉 촉

उ है घं

ํㅜㅇ

象羊焉

4 of

7 -

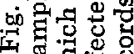

突莡出 

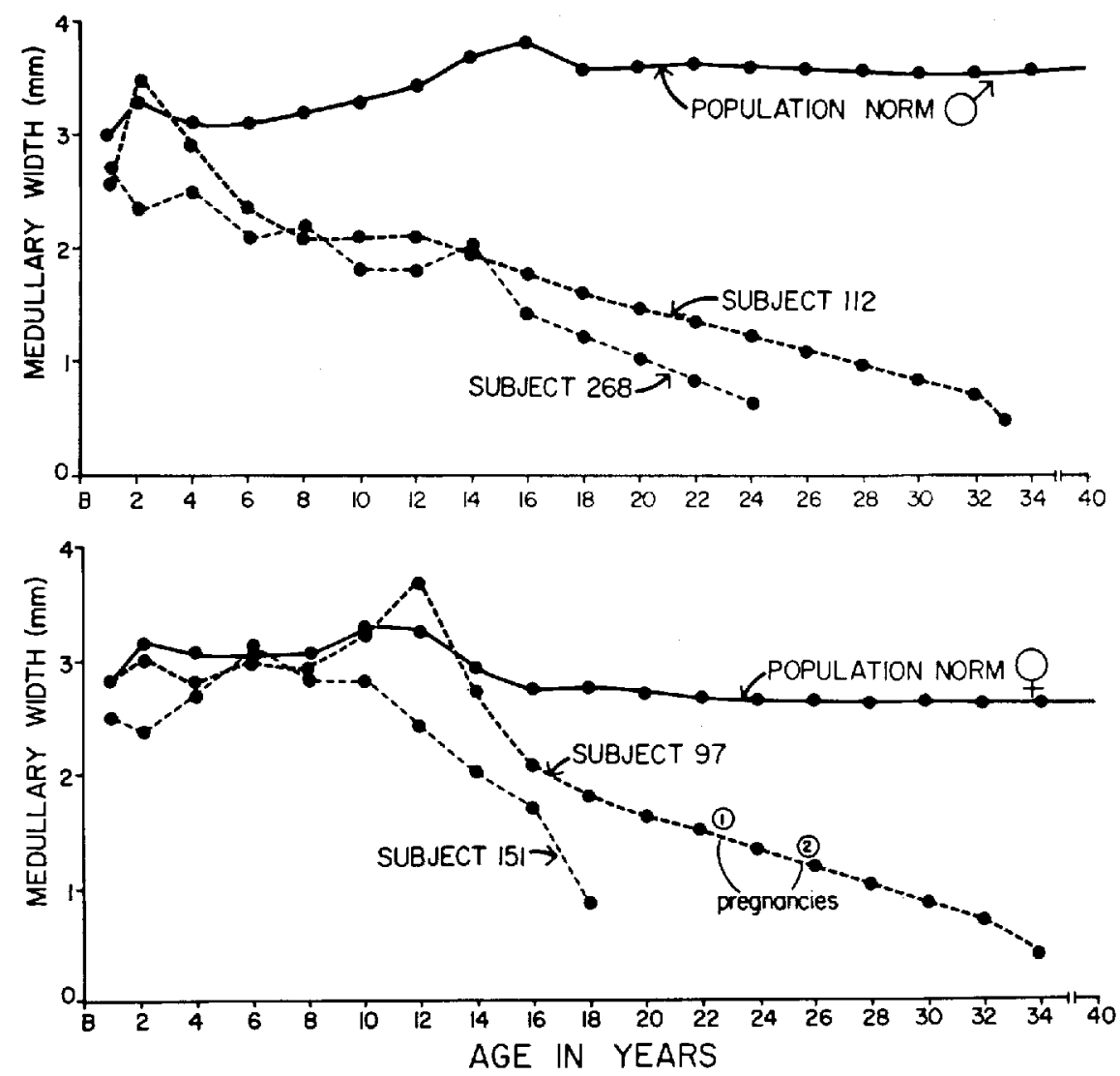

Fig. 2 Long-term changes at the endosteal surface in four subjects with extremely narrow adult medullary cavity widths. The two males (Subjects 112 and 268 , above) both undergo marked endosteal apposition from childhood on, the reverse of the normal course, and continue apposition at the endosteal surface, well into adulthood. The two females (subjects 097 and 151) evidence abnormally high rates of endosteal apposition during the steroidmediated phase of development, again continuing through adulthood and, for Subject 097, through two pregnancies. The population norm for medullary cavity width employed for comparison is that for Southwestern Ohio subjects of European ancestry.

\section{LITERATURE CITED}

Caffey, J. 1967 Congenital stenosis of medullary spaces in tubular bones and calvaria in two proportionate dwarfs - mother and son; coupled with transitory hypocalcemic tetany. Amer. J. Roentgenol, 100: 1-11.

Garn, S. M., C. G. Rohmann and G. Harshman 1968 Progress Report 68-1: Medullary stenosis in Central America. Fels Research Institute, Yellow Springs, Ohio.
Garn, S. M., C. G. Rohmann, B. Wagner and G. H. Davila 1968 Dynamics of change at the endosteal surface of tubular bones. Clin. Orthop., in press.

Kenny, F. M., and L. Linarelli 1966 Dwarfism and cortical thickening of tubular bones. Amer. J. Dis. Child., 3: 201-207.

Walker, H. M., and J. Lev 1953 Statistical Inference. Holt, Rinehart and Winston, New York. 